\title{
Night Blindness and the Mechanism of Constitutive Signaling of Mutant G90D Rhodopsin
}

\author{
Alexander M. Dizhoor, ${ }^{1}$ Michael L. Woodruff, ${ }^{2}$ Elena V. Olshevskaya, ${ }^{1}$ Marianne C. Cilluffo, ${ }^{3}$ M. Carter Cornwall, ${ }^{4}$ \\ Paul A. Sieving, ${ }^{5,6}$ and Gordon L. Fain ${ }^{2,7}$ \\ ${ }^{1}$ Hafter Research Laboratories, Pennsylvania College of Optometry, Salus University, Elkins Park, Pennsylvania 19027, ${ }^{2}$ Department of Physiological \\ Science, University of California, Los Angeles, Los Angeles, California 90095-1606, ${ }^{3}$ Brain Research Institute, David Geffen School of Medicine, University of \\ California, Los Angeles, Los Angeles, California 90095-1761, ${ }^{4}$ Department of Physiology and Biophysics, Boston University School of Medicine, Boston, \\ Massachusetts 02118-2526, ${ }^{5}$ National Eye Institute and ${ }^{6}$ National Institute on Deafness and Other Communication Disorders-National Institutes of Health, \\ Bethesda, Maryland 20892, and 7Jules Stein Eye Institute, David Geffen School of Medicine, University of California, Los Angeles, Los Angeles, California 90095-7000
}

The G90D rhodopsin mutation is known to produce congenital night blindness in humans. This mutation produces a similar condition in mice, because rods of animals heterozygous $(\mathrm{D}+)$ or homozygous $(\mathrm{D}+/+)$ for this mutation have decreased dark current and sensitivity, reduced $\mathrm{Ca}^{2+}$, and accelerated values of $\tau_{\mathrm{REC}}$ and $\tau_{\mathrm{D}}$, similar to light-adapted wild-type (WT) rods. Our experiments indicate that G90D pigment activates the cascade, producing an equivalent background light of $\sim 130 \mathrm{Rh}^{\star} \operatorname{rod}^{-1}$ for $\mathrm{D}+$ and $890 \mathrm{Rh}^{\star} \operatorname{rod}^{-1}$ for $\mathrm{D}+/+$. The active species of the G90D pigment could be unregenerated G90D opsin or G90D rhodopsin, either spontaneously activated (as Rh*) or in some other form. Addition of 11-cis-retinal in lipid vesicles, which produces regeneration of both WT and G90D opsin in intact rods and ROS membranes, had no effect on the waveform or sensitivity of dark-adapted G90D responses, indicating that the active species is not G90D opsin. The noise spectra of dark-adapted G90D and WT rods are similar, and the G90D noise variance is much less than of a WT rod exposed to background light of about the same intensity as the G90D equivalent light, indicating that Rh* is not the active species. We hypothesize that G90D rhodopsin undergoes spontaneous changes in molecular conformation which activate the transduction cascade with low gain. Our experiments provide the first indication that a mutant form of the rhodopsin molecule bound to its 11-cischromophore can stimulate the visual cascade spontaneously at a rate large enough to produce visual dysfunction.

Key words: photoreceptor; rod; transduction; adaptation; rhodopsin; vision

\section{Introduction}

Congenital night-blindness is a debilitating condition producing a profound loss of sensitivity of rod vision (Lem and Fain, 2004). In some patients the sensitivity loss is stable, but in others with increasing age some degeneration and permanent loss of function can occur. A particularly well studied form of autosomal dominant night-blindness is produced by the rhodopsin mutation Gly90Asp (G90D), in which a neutral glycine is replaced by acidic aspartate. Patients with this mutation have a persistent loss of rod sensitivity, similar to that produced by continuous background light (Sieving et al., 1995). Sieving et al. (1995) proposed that the

\footnotetext{
Received Aug. 22, 2008; accepted Sept. 30, 2008.

This work was supported by National Institutes of Health Grants EY11522 (A.M.D.), EY01157 (M.C.C.), EY01844 (G.L.F.), and EY 00331 [Jules Stein Eye Institute, University of California, Los Angeles (UCLA) Core, M.L.W., G.L.F.], National Eye Institute, National Institute on Deafness and Other Communication Disorders Intramural funding (P.A.S.), the Pennsylvania Lions Sight Preservation Foundation (A.M.D.), and the Microscopic Techniques Core Service Fund of UCLA (M.C.C.). A.M.D. is the Martin and Florence Hafter Chair Professor of Pharmacology. We thank Rosalie Crouch of the Medical University of South Carolina for providing 11-cis retinal, Roxana Radu of the Jules Stein Eye Institute, UCLA for assaying the purity of the retinal, Dean Bok and the members of the Bok laboratory of the Jules Stein Eye Institute, UCLA for providing tissue blocks of Rpe65 knock-out mice for measurement of outer segment dimensions, and Dan Tranchina of New York University for help with statistical testing.

Correspondence should be addressed to Dr. Gordon L. Fain, Department of Physiological Science, University of California, Los Angeles, 3836 Life Sciences, Los Angeles, CA 90095-1606. E-mail: gfain@ucla.edu. D01:10.1523/JNEUROSCI.4006-08.2008

Copyright $\odot 2008$ Society for Neuroscience 0270-6474/08/2811662-11\$15.00/0
}

mutant rhodopsin stimulates the transduction cascade, producing an equivalent background light and light adaptation. The aspartate in the mutant is known to be sufficiently close to perturb the salt bridge normally formed in wild-type rhodopsin between a glutamate residue and the lysine to which the chromophore binds (Rao et al., 1994; Rao and Oprian, 1996). This may give the dark form of G90D rhodopsin conformational properties similar to light-activated pigment, so that G90D rhodopsin may have partial activity even in darkness (Zvyaga et al., 1996). A role for G90D rhodopsin in producing the equivalent background is consistent with the observation of Sieving et al. (1995) that the desensitization in G90D patients is not reversed even after $12 \mathrm{~h}$ of dark adaptation.

Other experiments indicate, however, that the active species of G90D pigment may be opsin and not rhodopsin. Jin et al. (2003) expressed the G90D pigment at low concentration in Xenopus rods and showed that desensitization of the photoreceptors could be reversed by regeneration with 11-cis-retinal. This result supports G90D opsin as primarily responsible for the equivalent background, but it raises the question of why regeneration of pigment can restore sensitivity in Xenopus when even long periods of dark adaptation do not restore sensitivity in human G90D patients. In a separate series of experiments, Rao et al. (1994) showed that G90D opsin could activate transducin in vitro and 
that G90D rhodopsin had negligible activity. This also supports a role for G90D opsin, but the negative result for G90D rhodopsin is not definitive, because under similar assay conditions wild-type (WT) opsin also showed negligible activity (Robinson et al., 1992), and WT mouse opsin is known to be sufficiently active to produce robust stimulation of transduction when present in large quantities (Fan et al., 2005).

When the mammalian G90D pigment is expressed in Xenopus rods (Jin et al., 2003), it is considerably more active than when expressed in mouse (Sieving et al., 2001), indicating that the cellular environment of the protein may affect its properties. We have therefore re-examined the function of mammalian G90D pigment when expressed in a mammal. Our experiments show that the constitutive activity of the pigment in darkness is produced by G90D rhodopsin rather than G90D opsin, not by thermal transitions to highly active $\mathrm{Rh}^{\star}$ but rather by transition to a form that activates transduction at low gain.

\section{Materials and Methods}

Animals. Experiments were conducted in accordance with protocols approved by Institutional Animal Care and Use Committees. The G90D $(D+)$ mice in rhodopsin knock-out $($ Rho-/-) or a hemizygous (Rho+/-) rhodopsin background were produced as originally described by Sieving et al. (2001). We maintained the $D+/+; R h o-/-, D+/-$; Rho $-/-$ or $D+; R h o+/-$ mice as described previously (Sieving et al., 2001; Woodruff et al., 2007). The Rpe65 knock-out mice, originally generated by Redmond et al. (1998), were bred to Rho-/- mice (Humphries et al., 1997) and backcrossed to the Rho-/- to produce the Rpe65-/-;Rho-/- genotype. The primers for generating characteristic fragments from the Rho-/- knock-out allele of rhodopsin by PCR were 5'-AGGACTGACGGCTACTAACTGCCTTACAG-3' and 5'-GACCCGATACTCAGTGCCAT TACCTG-3'; primers for WT allele of rhodopsin were $5^{\prime}$-AGGACTGACGGCTACTAACTGCCTTACAG- $3^{\prime}$ and 5'-AGACCCGATACTCAGTGC CATTACCTG-3'. Primers for generating characteristic fragments for the wild-type allele of Rpe65 by PCR were $5^{\prime}$-CTCATCCTACAGCTGGTACCAGAACTCTCTCTA-3' and 5'-CAGAACTCTCTCTAATCTTCACTGGAAGAAAATGTCTA-3', and primers for generating products from the Rpe65 knock-out allele were $5^{\prime}$ TCACCAGAGTAGAGCCTATCTCAGTTC TTCT-3' and 5'-AGATTCTACCATTTCTTTCATTCTACAGTTGACA-3'. The double-knock-out mice all showed the knock-out allele-specific products but not the wild-type rhodopsin-specific or Rpe65-specific products.

We then crossed the Rpe65-/-;Rho-/- mice with $D+/+$;Rho-/mice and backcrossed the progeny to the Rpe65-/-;Rho-/- mice for several generations, to produce the triple hybrid, $D+/-$; Rpe65-/-; Rho-/- by selecting for the presence of the G90D rhodopsin transgene, the absence of the wild-type allele for Rpe65, and the presence of knockout alleles for both Rpe65 and the rod opsin gene. For G90D-specific PCR products, we used the same primers as in Woodruff et al. (2007).

It is important to emphasize that introduction of the G90D transgene (Sieving et al., 2001) made it impossible to verify by PCR or DNA restriction digest the absence of the characteristic products for the WT rhodopsin allele, because the G90D transgene was the whole rhodopsin gene encoding the point mutation in the rod opsin gene exon 1, randomly integrated into a mouse genome outside chromosome 6 (location of the rod opsin gene itself). The rhodopsin knock-out allele (Humphries et al., 1997), however, resulted from insertion of the neomycin-resistance cassette into the exon 2 of the rod opsin gene in chromosome 6 . This had the effect that, when we backcrossed the $D+/-; R p e 65-/-; R h o-/-$ mice to the Rpe65-/-;Rho-/- for several generations, the "wild-type"-specific PCR product from exon 2 always cosegregated with the G90D mutation in exon 1, demonstrating that products characteristic of the undisrupted exon 2 originated from the G90D transgene and not from a hemizygotic wild-type rhodopsin allele. Thus, any wild-type rhodopsin-specific products we detected must have been generated from exon 2 of the G90D rhodopsin transgene, because they were not found in the Rho-/- mice.
This confirmed that the wild-type rhodopsin gene was absent from our D+/-;Rpe65-/-;Rho-/- mice.

In addition to the $D+/-; R p e 65-/-; R h o-/-$ mice, we also produced a mouse with no wild-type rhodopsin allele that was heterozygous for the wild-type Rpe65 allele (Rho-/-; Rpe65+/-) and crossed it with the $D+/-$; Rpe65-/-; Rho-/- mice to generate the 11-cis-retinaldependent $D+/-$; Rpe65-/-; Rho-/- and 11-cis-retinal-independent $D+/-; R$ pe65+/-; Rho-/- mice in the same litters. These animals were used as the experimentals and controls for 11-cis-retinal applications in Figure $6 B$.

Histology. We killed mice by lethal injection of ketamine/xylazine solution and immediately perfused them through the heart with phosphate buffered saline followed by $2.5 \%$ glutaraldehyde in PBS. The eyes were excised with as little pressure on the ocular nerve as possible and placed in $2.5 \%$ glutaraldehyde $2.5 \%$ paraformaldehyde solution in $0.1 \mathrm{~m}$ cacodylate buffer, $\mathrm{pH}$ 7.4, where they were left overnight. They were then dehydrated, mounted in epon or paraffin, and sectioned and photographed as in Woodruff et al. (2007). Measurements of rod outer segment (ROS) dimensions were made as in Woodruff et al. (2007) and were obtained from Rpe65-/- retinas with tissue blocks kindly provided to us by Dean Bok of the Jules Stein Eye Institute (Los Angeles, CA); these blocks were the same as those used in the study of Redmond et al. (1998).

Suction-electrode recordings and free- $\mathrm{Ca}^{2+}$ determinations. Methods for recording responses of mouse rods have been given previously (Woodruff et al., 2007, 2008). When the $500 \mathrm{~nm}$ flashes were insufficiently bright to saturate the response (as for Rpe65-/- rods in Figs. 5, 6), we used white light as our stimulus. The intensity of the white light was calibrated individually for each different cell type by recording smallamplitude responses to white and $500 \mathrm{~nm}$ light and comparing their sensitivities. Intensities for the response-intensity curves of Figures $1 B$, $5 C$, and 6 were converted to numbers of rhodopsins bleached per flash from the collecting area of 0.5 for WT rods (Field and Rieke, 2002), adjusted for the difference in maximal pigment absorbance between WT rhodopsin (503 nm) and G90D rhodopsin (483 nm) (Rao et al., 1994; Zvyaga et al., 1996), and for differences in the lengths of outer segments of the mutants used in this study (see Results). No adjustment was made for outer segment diameter, because this was the same in mutant rods as in WT rods with one exception. The diameters of G90D rods also lacking the RPE65 protein were in general somewhat smaller than WT rods and the other G90D rods, but the shapes of the rods were so irregular that it was not possible to provide an accurate estimate of the mean diameter. We have therefore continued to use a diameter of $1.5 \mu \mathrm{m}$, although collecting areas and membrane areas used to calculate light intensities and current densities are likely to be overestimates by perhaps as much as $50 \%$. As we shall show in the Results section, this inaccuracy has little effect on the interpretation of our experiments. Current densities were calculated by dividing currents by total outer segment membrane area, calculated from the dimensions of the outer segments of WT and each of the mutant strains individually (Woodruff et al., 2007). Other information about the details of response presentation are given in the figure legends. Calcium was measured as described previously (Woodruff et al., $2002,2007)$. Unless otherwise stated, errors are given as SEs of the mean. Curve fitting and plotting of data were done with the program Origin (OriginLab).

Noise analysis. For WT rods, circulating current was recorded in darkness and in the presence of background light of 251 photons $\mu \mathrm{m}^{-2} \mathrm{~s}^{-1}$ $\left(125 \mathrm{Rh}^{*} \operatorname{rod}^{-1} \mathrm{~s}^{-1}\right)$, as well as in a saturating background of $7.9 \times 10^{3}$ photons $\mu \mathrm{m}^{-2} \mathrm{~s}^{-1}\left(4 \times 10^{3} \mathrm{Rh}^{*} \operatorname{rod}^{-1} \mathrm{~s}^{-1}\right)$. For $\mathrm{D}+$ rods, current was recorded only in darkness and in the presence of the saturating background. In darkness and for each light condition, data were acquired for 5 min in 30 segments of $10 \mathrm{~s}$ each at a sampling rate of $1 \mathrm{kHz}$ and filtered at $30 \mathrm{~Hz}$. Power spectra were calculated from the middle $9 \mathrm{~s}$ of each $10 \mathrm{~s}$ sweep, that is from 0.5 to $9.5 \mathrm{~s}$, thus limiting the low frequency resolution to $1 / 9 \mathrm{~s}^{-1}$ or $0.12 \mathrm{~Hz}$. Sweeps with an unstable baseline were omitted from the analysis, so that between 25 and 30 sweeps were used to calculate each spectrum. For each rod, the spectrum in saturating light (when all of the channels were closed) was subtracted from the spectrum in darkness or in the 251 photons $\mu \mathrm{m}^{-2} \mathrm{~s}^{-1}$ background light to remove instrumentation noise (Rieke and Baylor, 1996; Burns et al., 2002). Power spectra 

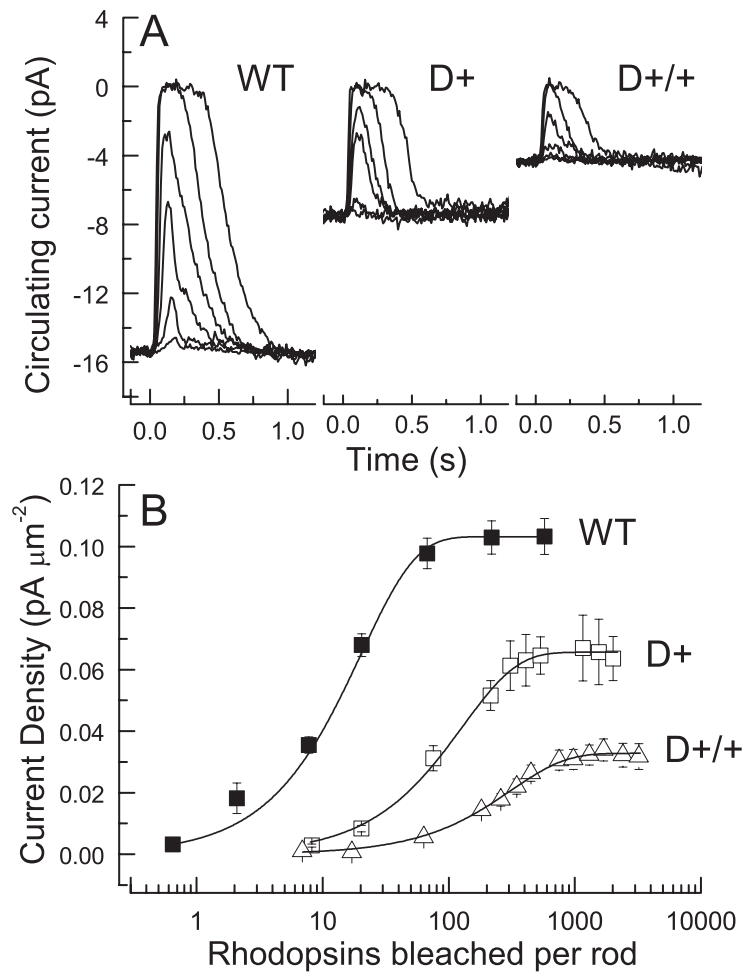

Figure 1. The rhodopsin G90D mutation decreases dark current and sensitivity. $\boldsymbol{A}$, Flash responses from single representative WT, G90D+/-;Rh+/- $(\mathrm{D}+)$ and $G 90 \mathrm{D}+/+$; $R h-/-(D+/+)$ rods. Light intensities of flashes were (in photons $\left.\mu \mathrm{m}^{-2}\right) 15,40,135,440$, 1150, and 4170; traces are averaged from 10 to 23 flashes at dimmer intensities and 5-10 flashes at brighter intensities. Flashes were $20 \mathrm{~ms}$, and interflash interval was 7-10 s. B, Mean intensity-response curves from rods that were WT (filled squares), G90D $+/-; R h+/-(D+$, unfilled squares) and $G 90 D+/+; R h-/-(D+/+$, unfilled triangles). WT data were averaged from 32 rods recorded as in $A$, with flash intensities from 1.3 to 4170 photons $\mu \mathrm{m}^{-2}$. D data were averaged from 10 rods with flash intensities from 17 to 4230 photons $\mu \mathrm{m}^{-2}$, and $\mathrm{D}+/+$ data were from 21 rods with intensities from 17 to 8060 photons $\mu \mathrm{m}^{-2}$. Error bars indicate SEs. Current densities were calculated by dividing by outer segment area, which was calculated from the length and diameter of the outer segment without taking into account the incisures or infolded disks at the outer segment base. Areas were $113 \mu \mathrm{m}^{2}$ for WT and D+, and $99 \mu \mathrm{m}^{2}$ for D $+/+$ (see Results). Numbers of rhodopsins bleached were calculated from light intensities by multiplying by collecting area. This was taken as $0.5 \mu \mathrm{m}^{2}$ for WT rods (Field and Rieke, 2002). For G90D rods, a correction was made for outer segment length and the different peak absorption of the G90D photopigment (see Results). Collecting areas were 0.48 for $D+$ and 0.40 for $D+/+$. Curves are exponential saturations functions given by Equation 1 in text, with the following $k$ values: 0.049 for WT, 0.0078 for $D+$, and 0.0030 for $D+/+$.

were computed with ClampFit software (Molecular Devices); traces shown in Figure 8 are the averaged difference spectra for $12 \mathrm{WT}$ and 12 G90D rods with SEs of the mean.

Application of 11-cis-retinal to intact photoreceptors. The 11-cis-retinal was made available to us by the laboratory of Rosalie Crouch of the Medical University of South Carolina (Charleston, South Carolina). The purity of the compound was assayed with HPLC by Roxana Radu of the Jules Stein Eye Institute at UCLA and was found to be $98.6 \%$ 11-cisretinal and $1.4 \%$ all-trans retinal. Crystals of retinoid were dissolved in $100 \%$ (absolute) ethanol in dim red illumination at $1 \mathrm{mg}$ in $100 \mu \mathrm{l}$ solvent to obtain a final concentration of $\sim 10 \mathrm{mg} / \mathrm{ml}$. The exact concentration of the retinoid solution was determined by difference spectroscopy as explained below. The solution was divided into three equal portions by pipetting into conical-bottomed glass vials. The ethanol was evaporated away completely under a stream of $\mathrm{N}_{2}$ gas, and the dried retinoid was stored in $\mathrm{a}-80^{\circ} \mathrm{C}$ freezer until used in an experiment.

On the morning of the experiment, lipid vesicles were prepared as a vehicle for the retinoid. The vesicles were made as follows: $0.25 \mathrm{ml}$ of L- $\alpha$ phosphatidylcholine (Sigma; P2772) was placed in a liquid scintillation vial and dried evenly against the bottom of the vial under a gentle stream of $\mathrm{N}_{2}$ gas. Then $10 \mathrm{ml}$ of Locke's solution ( $140 \mathrm{~mm} \mathrm{NaCl}, 3.6 \mathrm{~mm} \mathrm{KCl}, 2.4$ $\mathrm{mm} \mathrm{MgCl}, 1.2 \mathrm{~mm} \mathrm{CaCl}_{2}, 20 \mu \mathrm{M}$ EDTA, 3 mм Hepes, brought to $\mathrm{pH} 7.4$ with $\mathrm{NaOH}$ ) was added to the vial and sonicated with a VibraCell sonicator (Sonics \& Materials) having a large diameter probe tip (12.5 mm). The vial was cooled by immersion in an ice bath, and the solution was sonicated usually for three 10 min periods at an $80 \%$ setting of the sonicator $(100 \mathrm{~W})$ until the solution turned from milky to opalescent. A 1.5 $\mathrm{ml}$ aliquot of sonicated vesicles was added to one of the conical glass vials with dried retinoid and sonicated with a small tip probe for $\sim 4$ min at $30-50 \mathrm{~W}$. From this, $25 \mu \mathrm{l}$ was removed to $475 \mu \mathrm{l}$ of absolute ethanol, and the retinoid content was assayed in a scanning spectrophotometer (UV-2101 PC; Shimadzu) and calculated from the published extinction coefficient. A portion of the solution containing the retinoid in lipid vesicles was then diluted into Locke's solution to obtain the final desired retinoid concentration.

The two eyes of a mouse were divided into four pieces, and the retinas of each were dissociated. One preparation was used for immediate recording, and the others were used for vesicle incubation. Rpe65-/- rods were incubated with vesicles for between 30 and $60 \mathrm{~min}$, and $D+/-$; Rho-/-;Rpe65-/- rods for from 1 to $3 \mathrm{~h}$. At the end of each of the incubation periods, the rod preparations were pipetted into the recording chamber and perfused for 5-10 min before the recordings were begun to remove any remaining lipid vesicles.

Application of 11-cis-retinal to ROS membranes. We isolated the bulk photoreceptor outer-segment fraction from mouse retinas with discontinuous density gradient using previously described protocols (Tsang et al., 1998, Burns et al., 2006) but with the following modifications. Retinas (usually 12) from mice dark-adapted for 12-18 h were collected under infrared light on ice in $15 \mu \mathrm{l}$ of high-glucose DMEM without phenol red (Invitrogen). Pooled retinas were mixed with $250 \mu \mathrm{l}$ of $8 \%$ Optiprep iodoxanol solution in DMEM containing $100 \mu \mathrm{M}$ phenylmethanesulphonylfluoride, vortexed for $2 \mathrm{~min}$, and centrifuged at $1000 \mathrm{rpm}$ for 1 min. The supernatant was collected, and the extraction procedure was repeated two more times with $150 \mu \mathrm{l}$ of the $8 \%$ Optiprep solution. The combined fraction of the supernatant was loaded on a two-step $(18 / 10 \%$ Optiprep in DMEM) density gradient and centrifuged for $1.5 \mathrm{~h}$ at 50,000 $\mathrm{rpm}$ in a Beckman TLS-55 swing-bucket rotor at $4^{\circ} \mathrm{C}$. The band of outer segments was collected from the gradient, diluted fourfold with $20 \mathrm{~mm}$ TrisHCl, pH7.5, $130 \mathrm{~mm} \mathrm{NaCl}, 8 \mathrm{~mm} \mathrm{KCl}, 5 \mathrm{~mm} \mathrm{MgCl}_{2}$, and pelleted by centrifugation for $20 \mathrm{~min}$ at $45,000 \mathrm{rpm}, 4^{\circ} \mathrm{C}$. The pellet was resuspended in the same buffer solution, aliquoted and stored frozen in liquid nitrogen or in $-70^{\circ} \mathrm{C}$ until use. All isolation procedures were conducted with prechilled ice-cold solutions under infrared light except for the retinas from the Rpe65-/- genetic background, which were collected under normal ambient light.

ROS membranes isolated in the light containing either wild-type or G90D rhodopsin in a Rpe65-/- genetic background were incubated in the dark for $1 \mathrm{~h}$ at $37^{\circ}$ in the presence of $500 \mu \mathrm{M}$ 11-cis-retinal, washed with $10 \mathrm{~mm}$ Tris $\mathrm{HCl}, 100 \mathrm{~mm} \mathrm{NaCl}$, and dissolved in $2 \mathrm{~mm}$ octylglucoside containing $1 \mathrm{~mm}$ freshly prepared hydroxylamine, $\mathrm{pH}$ 7.5. The absorbance measurements were done at $500 \mathrm{~nm}$ in a $0.1 \mathrm{ml}$ spectrophotometric cuvette in a Beckman DU68 spectrophotometer before and after complete bleaching of the sample in the cuvette with a focused flashlight. The concentration of rhodopsin was calculated from the difference absorbance with a molar extinction coefficient for both G90D and wild-type rhodopsin of 40,000, and the concentration of G90D pigment was corrected for the 0.91 absorbance efficiency at $500 \mathrm{~nm}$ relative to the wildtype rhodopsin. There was no detectable pigment before the regeneration with 11-cis-retinal in ROS from the Rpe65-/- background. After the concentrations were determined, equal amounts of WT and G90D pigment were loaded onto an SDS gel in the light in amounts of 17.6, 35.3 and $53 \mathrm{ng}$, and the opsin was then subjected to immunoblotting with an antirhodopsin polyclonal antibody. The strength of the immunoblot signal was measured with chemilumiscence and quantified by densitometry as described previously (Olshevskaya et al., 2004; Woodruff et al., 2007). The comparison of WT with $D+/+; R-/-$ mice in the Rpe+ background was conducted by a similar procedure but with dark ROS membranes from dark-adapted mice. 
Table 1. Kinetic properties of WT and G90D rods

\begin{tabular}{|c|c|c|c|c|}
\hline & Integration time (ms) & $\tau_{\mathrm{REC}}(\mathrm{ms})$ & $\tau_{\mathrm{D}}(\mathrm{ms})$ & $S_{\mathrm{F}}^{\mathrm{D}}\left(\mathrm{pA}\right.$ photon $\left.{ }^{-1} \mu \mathrm{m}^{2}\right)$ \\
\hline WT & $246 \pm 13(112)$ & $190 \pm 12(115)$ & $193 \pm 8(57)$ & $0.295 \pm 0.013(126)$ \\
\hline $\mathrm{G} 90 \mathrm{D}+1-; \mathrm{Rh}+/-$ & $110 \pm 11(28)$ & $94 \pm 6(33)$ & $135 \pm 7(26)$ & $0.027 \pm 0.002(36)$ \\
\hline G90D + / +;Rho-I- & $108 \pm 10(18)$ & $70 \pm 12(19)$ & $96 \pm 8(17)$ & $0.0045 \pm 0.0004(21)$ \\
\hline
\end{tabular}

Errors are SE. Numbers in parentheses are numbers of cells.

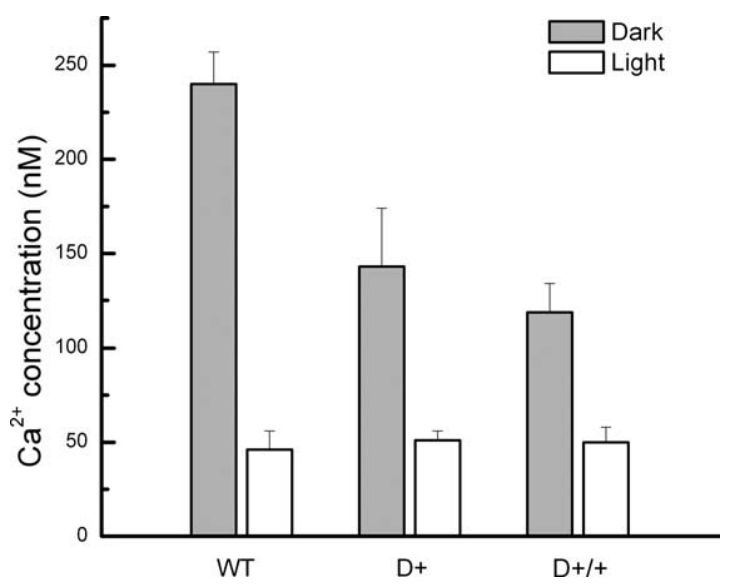

Figure 2. Measurement of free $\mathrm{Ca}^{2+}$ concentration from outer segments of WT, D+ and $D+/+$ rods. Error bars indicate SE. See Results.

\section{Results}

We recorded and compared the light responses to brief flashes from dark-adapted WT, G90D+/-;Rh+/- (D+), and G90D+/ $+; R h o-/-(\mathrm{D}+/+)$ rods. We detected no evidence of degeneration in $\mathrm{D}+$ retinas at any animal age (Sieving et al., 2001; Naash et al., 2004). In $D+/+; R h o-/-$ retinas, we detected a small decrease in photoreceptor cell number in older animals (supplemental Fig. $1 A, B$, available at www.jneurosci.org as supplemental material) unlike previous observations (Sieving et al., 2001; Naash et al., 2004). In agreement with those studies, however, we found no evidence of cell loss in animals at the ages used in our recordings (between 1 and 4 months old).

The traces in Figure $1 A$ show typical averaged responses for a series of increasing flash intensities from a single rod of each kind. The most prominent difference is the value of the circulating current in darkness, which is smaller than WT for the D+ rod and smaller still for the $\mathrm{D}+/+$ photoreceptor. The responses of the mutant rods were also considerably less sensitive (Table 1). This is easier to see from the curves in Figure $1 B$, which plot mean peak response amplitude as a function of flash intensity averaged from $32 \mathrm{WT}, 10 \mathrm{D}+$, and $21 \mathrm{D}+/+$ rods. We adjusted the collecting areas of the G90D rods for the somewhat shorter outer segments of the $\mathrm{D}+/+$ rods $(20-22 \mu \mathrm{m}$ instead of $24 \mu \mathrm{m})$ (Sieving et al., 2001), and for the difference in peak absorption of the G90D pigment, which is at $483 \mathrm{~nm}$ instead of at $503 \mathrm{~nm}$ (Rao et al., 1994; Zvyaga et al., 1996). This decreases the probability of absorption of our $500 \mathrm{~nm}$ stimulus by a factor of 0.91 by comparison to the WT pigment for $\mathrm{D}+/+$ and 0.95 for $\mathrm{D}+$ (assuming equal expression of the two pigments). Currents have been plotted as current densities to compensate for the somewhat smaller outer segments of the $\mathrm{D}+/+$ rods; we have assumed that that there is no difference in channel density per unit outer segment area between the WT and the various mutant photoreceptors. The data have been fitted with exponential saturation functions (Lamb et al., 1981) of the following form:

$$
i=i_{\max }[1-\exp (-k I)]
$$

where $i$ is the photocurrent, $i_{\max }$ the maximum value of the photocurrent, $I$ the flash or step intensity, and $k$ a constant. Values for $k$ are given in the figure legend.

The peak values of the current densities for the three kinds of photoreceptors were $0.103(\mathrm{WT}), 0.065(\mathrm{D}+)$, and $0.033(\mathrm{D}+/+) \mathrm{pA} \mu \mathrm{m}^{-2}$ and are in the ratio of 1:0.6:0.3. Because our previous studies have shown that decreases in current density produce nearly commensurate decreases in outer segment free- $\mathrm{Ca}^{2+}$ concentration (Woodruff et al., 2007), we expected that the $\mathrm{Ca}^{2+}$ would also be diminished in the G90D rods. We tested this supposition by measuring the concentration of $\mathrm{Ca}^{2+}$ in the rod outer segment with the fluorometric dye fluo-5F, using methods we have previously described (see Materials and Methods) (Woodruff et al., 2002, 2007). The results of these experiments are given in Figure 2. The $\mathrm{Ca}^{2+}$ concentration was significantly lower in both $\mathrm{D}+$ and $\mathrm{D}+/+$ rods than in WT ( $p=0.05$ level, two-tailed Student's $t$ test), although the difference between $\mathrm{D}+$ and $\mathrm{D}+/+$ was not significant $(p=$ 0.51 , two-tailed Student's $t$ test). The mean dark $\mathrm{Ca}^{2+}$ concentrations $(240,143$, and $119 \mathrm{nM})$ were in the ratio of 1:0.6:0.5. The current-density measurements would predict a lower value for the dark $\mathrm{Ca}^{2+}$ of $\mathrm{D}+1+$ rods of $\sim 72 \mathrm{nM}$, and the measured mean $\mathrm{Ca}^{2+}$ of $119 \mathrm{nM}$ is significantly higher than this ( $p=0.01$ level, two-tailed Student's $t$ test). The reason for the discrepancy is unknown. The $\mathrm{Ca}^{2+}$ concentrations in bright light were $46 \pm 10$ $\mathrm{nm}(\mathrm{WT}), 51 \pm 5 \mathrm{~nm}(\mathrm{D}+)$, and $50 \pm 8 \mathrm{~nm}(\mathrm{D}+/+)$ and were not significantly different from one another.

\section{The intensity of the equivalent background light}

Because the G90D mutation reduces circulating current and sensitivity, it acts much like a continuous equivalent background light. We estimated the intensity of this equivalent background by comparing the change in sensitivity in $\mathrm{D}+$ and $\mathrm{D}+/+$ rods $(\mathrm{Ta}-$ ble 1 ) to that produced in a WT rod by a steady adapting background light. We (Fan et al., 2005; Woodruff et al., 2008) and others (Mendez et al., 2001; Makino et al., 2004) have previously shown that the sensitivity of mouse WT rods decreases in steady backgrounds according to the Weber relation:

$$
\frac{S_{F}}{D_{F}^{D}}=\frac{I_{0}}{I_{0}+I_{B}},
$$

where $S_{F}$ is the flash sensitivity of the rod, $S_{F}^{D}$ the flash sensitivity in darkness, $I_{B}$ the intensity of the background, and $I_{O}$ a constant. Using a value for $I_{O}$ of 30 photons $\mu \mathrm{m}^{-2} \mathrm{~s}^{-1}$ (Woodruff et al., 2008) and the sensitivity measurements in Table 1, we calculated that the intensity of the background light in a WT rod necessary to produce the same desensitization we observed in G90D rods is 264 photons $\mu \mathrm{m}^{-2} \mathrm{~s}^{-1}$ (or $\left.\sim 130 \mathrm{Rh}^{*} \operatorname{rod}^{-1} \mathrm{~s}^{-1}\right)$ for $\mathrm{D}+$ and 1788 photons $\mu \mathrm{m}^{-2} \mathrm{~s}^{-1}$ (or $\sim 890 \mathrm{Rh}^{\star} \operatorname{rod}^{-1} \mathrm{~s}^{-1}$ ) for $\mathrm{D}+/+$. The value for $\mathrm{D}+$ is probably within experimental error of the estimate of $82 \mathrm{Rh}^{*}$ rod $^{-1} \mathrm{~s}^{-1}$ made by Sieving et al. (2001) for this same mouse line from measurements of the isolated a-wave.

\section{Changes in response kinetics in $\mathrm{D}+$ and $\mathrm{D}+/+$ rods}

If the expression of the G90D pigment has the effect of producing an equivalent background light, it would be expected to have a marked effect on the kinetics of the rod light response. In Figure 3, we compare the waveforms of responses to a series of flashes of fixed intensity. Responses were normalized cell by cell, and the 
normalized waveforms were then averaged for WT rods (black traces), D+ rods (blue traces), and $\mathrm{D}+/+$ rods (red traces). The responses of the $\mathrm{D}+$ and $\mathrm{D}+/+$ are smaller except at the brightest flashes, reflecting their reduced sensitivity to light (Fig. $1 B$ ). In addition, the $\mathrm{D}+$ and $\mathrm{D}+/+$ rods have shorter integration times and decay more rapidly (Sieving et al., 2001; Woodruff et al., 2007).

We give values of some of the kinetic parameters of the rods in Table 1. All of the values in the table for $\mathrm{D}+$ and $\mathrm{D}+/+$ rods were significantly different from WT ( $p=$ 0.05 level, two-tailed Student's $t$ test), and all of those of $\mathrm{D}+$ were significantly different from those of $\mathrm{D}+/+$ at the 0.05 level or greater except for the integration times in the second column. The decreases in $\tau_{\mathrm{REC}}$ are consistent with the increased rate of response decay illustrated in Figure 3. Together with the decreases in sensitivity, they support the hypothesis of Sieving et al. (1995) that rods containing G90D rhodopsin act as if in the presence of a background light even when no light is present.

\section{Decreases in the limiting time constant $\tau_{\mathrm{D}}$}

Recent experiments (Woodruff et al., 2008) indicate that in mouse rods, steady background light produces a decrease in the limiting time constant of response decay, known as the "Pepperberg constant" (Pepperberg et al., 1992) or $\tau_{\mathrm{D}}$. Because the results in Figures 1-3 indicate that the G90D mutation decreases photoreceptor sensitivity, $\mathrm{Ca}^{2+}$ concentration, and $\tau_{\mathrm{REC}}$ much as if the rod were in the presence of background illumination, we asked whether $\tau_{\mathrm{D}}$ might also be altered. In Figure 4, we show responses of representative $\mathrm{WT}(A), \mathrm{D}+(B)$, and $\mathrm{D}+/+(C)$ rods to a series of saturating responses of increasing intensity. The time during which the response remained in saturation for each of the flashes was smaller for the D+ rod than for WT, and smaller again for the $\mathrm{D}+/+$ rod. A horizontal line was drawn at a criterion level of $75 \%$ of the maximum value of the photocurrent, and the time in saturation, $\mathrm{T}_{\text {sat }}$, was calculated as the time required after the presentation of the flash for the response to decay to this criterion value. The slope of the best linear fit to $\mathrm{T}_{\text {sat }}$ as a function of the natural logarithm of the flash intensity is an estimate of $\tau_{\mathrm{D}}$, the ratelimiting time constant for the decay of the response (Pepperberg et al., 1992). The values of $\tau_{\mathrm{D}}$ for individual cells in Figure $4 A, B, C$ were $224 \mathrm{~ms}, 138 \mathrm{~ms}$, and $97 \mathrm{~ms}$.

In Figure $4 D$, we give mean values (with SEs) for $\mathrm{T}_{\text {sat }}$ from 26 WT rods (circles), $28 \mathrm{D}+$ rods (squares), and $18 \mathrm{D}+/+$ rods (triangles) as a function of the natural logarithm of intensity. The slopes fitted to the mean values gave values for $\tau_{\mathrm{D}}$ of $183 \mathrm{~ms}$ (WT), $122 \mathrm{~ms}(\mathrm{D}+)$, and $105 \mathrm{~ms}(\mathrm{D}+/+)$. In Table 1, we give means with SE's for individual determinations of $\tau_{\mathrm{D}}$ for the three different cell types. The three values were each significantly different from one another ( $p=0.01$ level, two-tailed Student's $t$ test). These data together with the recordings in Figure 4 show that rhodopsin G90D produces a marked decrease in the limiting time constant, much like constant background light (Woodruff et al., 2008), and that the decrease in $\tau_{\mathrm{D}}$ is greater in animals with two G90D genes than when only a single mutant gene is present.

\section{Addition of 11-cis-retinal restores sensitivity of Rpe65} knock-out rod

The results of Figures $1-4$ show that $\mathrm{D}+$ and $\mathrm{D}+/+$ rods behave as if in the presence of an equivalent background produced in some way by the mutant pigment. The experiments of Jin et al. (2003) on G90D rhodopsin expressed in Xenopus rods show that sensitivity and $\tau_{\mathrm{REC}}$ can be increased and returned nearly to their dark-adapted values after addition of exogenous 11-cis-retinal, suggesting that the equivalent background is produced by unregenerated opsin. To perform similar experiments on mouse rods, we needed first to establish a reliable method for applying 11-cisretinal to intact mammalian rods in vitro.

In Figure 5, we show the results of the application of lipid vesicles containing 11-cis-retinal to rods from mice lacking the RPE65 isomerase protein. Previous experiments have shown that rods from Rpe65-1- mice raised in cyclic light contain abundant opsin but little or no rhodopsin (Redmond et al., 1998) and only a small amount of functional visual pigment in the form of isorhodopsin with the 9-cis-retinal chromophore (Fan et al., 2003). The opsin in Rpe65-/- mice can be regenerated, at least in vivo, because when Rpe65-/- mice are given 9-cis-retinal orally, the rods can recover much of their sensitivity (Van Hooser et al., 2002).

We now show that Rpe65-/- opsin can also be regenerated in an isolated rod. Our method for preparing lipid vesicles containing 11-cis-retinal is similar to one previously used for amphibian rods (Cornwall et al., 2000). Vesicles were made from phosphatidylcholine and sonicated in the presence of retinal (see Materials and Methods). Both eyes from a dark-adapted mouse were di- 


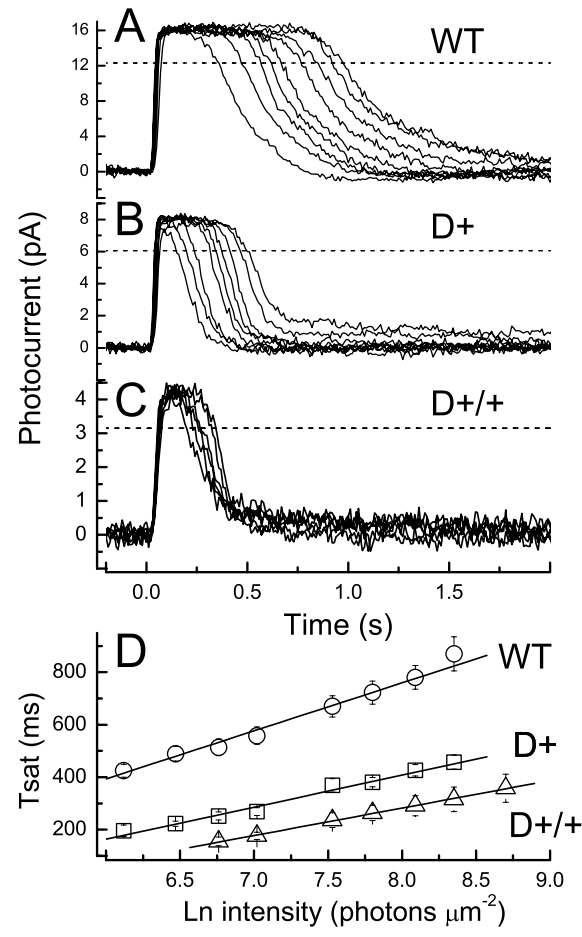

Figure 4. $\quad A-C$, Responses from individual WT $(A), D+(B)$, and $D+/+(C)$ rods to a series of saturating flashes of increasing intensity. Each trace is the mean response to five $20 \mathrm{~ms}$ flashes. The light intensities for $A$ were $160,450,645,865,1120,1870,2430,3250$, and 4230 photons $\mu \mathrm{m}^{-2}$; those for $\boldsymbol{B}$ were $450,645,865,1120,1870,2430,3250,4230$, and 6030 photons $\mu \mathrm{m}^{-2}$; and those for $C$ were 1870, 2430, 3250, 4230,6030, and 8060 photons $\mu \mathrm{m}^{-2}$. The dashed line in each panel marks $25 \%$ of the dark circulating current for each rod, which was the criterion we used to estimate the length of time the rods remained in saturation $\left(T_{\text {sat }}\right)$. D, Mean $\mathrm{T}_{\text {sat }}$ with SE estimated from 26 WT rods (circles), $28 \mathrm{D}+$ rods (squares), and $18 \mathrm{D}+/+$ rods (triangles) as a function of the natural log of flash intensity. Error bars indicate SE. Lines are best-fitting linear functions with slopes of $183 \mathrm{~ms}(\mathrm{WT}), 122 \mathrm{~ms}(D+)$, and $105 \mathrm{~ms}(\mathrm{D}+/+$ ). For means and SEs of individual determinations of $\tau_{D}$, see Table 1.

vided in half, and the four retinal pieces were individually dissociated mechanically. One of the four resulting pieces was used for immediate recording, and the other three were incubated in the presence of 11-cis-retinal for 1-3 h.

In Figure $5 A$, we show the response to a flash of $4.9 \times 10^{4}$ photons $\mu \mathrm{m}^{-2}$ averaged from 17 Rpe65-/- rods not incubated in 11-cis-retinal (blue trace), and from a different 17 Rpe65-Irods to a much dimmer flash of 43 photons $\mu \mathrm{m}^{-2}$ after vesicle treatment (red trace). Data from rods incubated for $1-3 \mathrm{~h}$ were combined, because we could observe no significant difference in the amplitude or waveform of the responses for the different times of vesicle exposure. Incubation with 11-cis-retinal produced an increase in the sensitivity of the rod by more than three orders of magnitude. The waveform was also altered. In Figure $5 B$, the responses from Figure $5 A$ have been individually normalized to the peak amplitude of the response cell by cell, and the normalized results were averaged separately for the responses of each kind. The waveform of decline of the Rpe65-/ - response is accelerated, as reported previously (Woodruff et al., 2003); a fit of the declining phase of the response with a single exponential decay function (black curve) gave a value for $\tau_{\mathrm{REC}}$ of $75 \mathrm{~ms}$. After addition of retinal, the response decayed less rapidly, and the best-fitting value for $\tau_{\text {REC }}$ was $164 \mathrm{~ms}$, much closer to previously recorded values from dark-adapted WT rods (Table 1) (Krispel et al., 2006). This difference is highly significant ( $p=0.0003$, twotailed Student's $t$ test).
In Figure $5 C$, we show response-intensity curves for Rpe65-I- rods before (blue symbols) and after (red symbols) incubation with 11-cis-retinal. Current densities were calculated as in Figure $1 B$; measurements of outer segment length of Rpe65-/- gave a mean value of $15.1 \pm 0.5 \mu \mathrm{m}$. Intensities in units of photons $\mu \mathrm{m}^{-2}$ have been converted to rhodopsins bleached by multiplying by the collecting area adjusted for the shorter length of the outer segments. The collecting area for the rods before incubation was also corrected for the relative absorption of isorhodopsin at $500 \mathrm{~nm}$ (0.95), and the lower quantum efficiency of 9-cis-retinal-based pigments ( 0.22 vs 0.67 ) (Hurley et al., 1977). Incubation with 11-cis-retinal produced a large shift of the response-intensity curve to dimmer intensities. The black symbols and curve are for dark-adapted WT rods and have been taken from Figure $1 B$. Incubation with 11-cis-retinal can be seen to bring the sensitivity to a value not significantly different from that of a WT dark-adapted rod, indicating that our method can regenerate essentially all of the pigment in the photoreceptor. Further evidence for this will be given below (see Fig. 7).

\section{Addition of 11-cis-retinal to G90D rods}

Having established that we were able to regenerate mouse visual pigment, we next delivered the 11-cis-retinal to $\mathrm{D}+$ and $\mathrm{D}+/+$ rods. Figure $6 A$ shows the effects on $\mathrm{D}+/+$; similar results were obtained from $\mathrm{D}+$ (data not shown). Response-intensity curves have been plotted as in Figure $1 B$ with appropriate corrections for outer segment length and collecting area, and the results have been given as in Figure $5 C$ for rods before (open squares) and after (open circles) incubation with vesicles containing chromophore. The response-intensity data for WT rods from Figure $1 B$ (filled circles) are also given for comparison. Although the exponential saturation curves fitted to the data for $\mathrm{D}+/+$ rods showed a small shift to lower intensities after addition of vesicles, this shift was not significant. When individual cells were separately fitted and the values of the light intensities at half saturation were compared, the values before and after application of 11-cisretinal were not significantly different (Wilcoxon Rank-Sum test, $p$ value $=0.2077$ ). We also observed no change in the decay phase of the waveform of the response. Values for $\tau_{\text {REC }}$ before and after application of retinal from the rods used in these experiments were $98 \pm 11 \mathrm{~ms}$ and $92 \pm 10 \mathrm{~ms}$ and were again not significantly different ( $p=0.75$, two-tailed Student's $t$ test). On three occasions, we used the same population of lipid vesicles on the same day for Rpe65-/- rods (as in Fig. 5) and G90D rods, and in each case we saw a large increase in sensitivity for the former but no significant change for the latter.

Because the rate of regeneration of G90D rhodopsin has been shown to be considerably slower than of WT rhodopsin (Gross et al., 2003), it seemed possible that our failure to alter the sensitivity of G90D rods was the result of slow binding of chromophore to the visual pigment, although a similar experiment produced a large change in sensitivity and apparently complete regeneration of the pigment in Xenopus rods. We therefore made animals that contained the G90D mutation but lacked the Rpe65 isomerase, because these mice, like the Rpe65-/ - animals with WT pigment in Figure 5, should have rods with very little pigment bound to chromophore but abundant opsin (although G90D opsin). These animals were developed through multistep mating of G90D mice to Rpe65-/- and Rho-/- mice, as described in Materials and Methods, to produce animals that contained only a single gene for G90D, no functional genes for WT rhodopsin, and no functional genes for the Rpe65 isomerase. $D+/-$;Rho-/-; Rpe65-/- rods showed a progressive degeneration of the outer 
nuclear layer over a 7 month period, but they remained in sufficient abundance and were suitable for single-cell recording at younger ages (supplemental Figure $1 D$, top, available at www.jneurosci.org as supplemental material).

The results of these experiments are given in Figure $6 B$. The filled squares show current density as a function of light intensity for the $D+/-; R h o-/-; R p e 65-/-$ rods. Current density was calculated by dividing by the outer segment area, which was measured from animals of the same age and littermates of those used for the physiology. The outer segment length was determined to be $8.6 \pm 3 \mu \mathrm{m}$, about a third that of WT rods. Outer segments had disks with disorganized packing and an irregular shape. This precluded an accurate determination of outer segment diameter, and our values for outer segment membrane area and collecting area (which assumed a diameter of $1.5 \mu \mathrm{m}$ ) are likely to be overestimates by as much as $50 \%$. It was nevertheless clear that the responseintensity curve for the $D+/-; R h o-/-$; Rpe65-/- rods, which have a large proportion of G90D opsin and little G90D rhodopsin, is not much displaced along the intensity axis from the curve for Rpe65-/- rods (Fig. 5C, blue squares), which contain almost entirely WT opsin. This indicates that G90D opsin in vivo is unlikely to be much more active in stimu-

lating the cascade than WT opsin, at variance with the measurements of Rao et al. (1994) for WT and G90D visual pigments in vitro. If the G90D opsin in vivo were as active as Rao et al. (1994) said it to be in vitro, the $D+/-; R h o-/-; R p e 65-/-$ rods would have been completely saturated and no light responses would have been recorded (see Discussion).

The closed triangles in Figure $6 B$ give the mean responseintensity curve of the $D+/-; R h o-/-; R p e 65-/-$ rods after incubation with vesicles containing 11-cis-retinal. The addition of chromophore produced an increase in both the maximum value of the current density and in the sensitivity. The increase in sensitivity is not as large as for the Rpe65-/- rods containing WT rhodopsin (Fig. 5C), because the rhodopsin that was formed in the rods of Figure $6 B$ after the addition of vesicles was G90D rhodopsin. Further support for this notion comes from comparison with the open squares, which give mean response-intensity data for $5 \mathrm{D}+/-$; Rho $-/-$ rods prepared as a control, having a similar genetic make-up to $D+/-; R h o-/-; R p e 65-/-$ rods but with a single copy of the functional Rpe65 gene (see Materials and Methods). A single copy of the Rpe65 gene is known to be sufficient to produce normal levels of 11-cis-retinal and functional rhodopsin (Van Hooser et al., 2000), and the outer segments from these animals were much larger $(14.7 \pm 1.7 \mu \mathrm{m})$ and more regularly formed with a normal diameter. Their current density as a function of rhodopsin molecules bleached (open squares) was nearly identical to that of the regenerated $D+/-; R h o-/-$; Rpe65-/- rods (filled triangles). The small difference may be the result of our inability to provide a more accurate estimate of the collecting area of the $D+/-; R h o-/-; R p e 65-/-$ rods, because, had we used a smaller diameter to calculate collecting area and outer segment membrane area, the filled triangles in Figure $6 \mathrm{~B}$ would have moved upward and to the left, in closer agreement with the open squares.

The open circles in Figure $6 B$ give mean response-intensity data from 4 rods from the same animals as those for the open squares but after incubation with 11-cis-retinal. As for the G90D rods in Figure $6 \mathrm{~A}$, addition of 11-cis-retinal produced no significant change in circulating current density or sensitivity. This cannot however be the result of our inability to regenerate the visual pigment, because when the G90D pigment is present predominantly as opsin rather than as rhodopsin (filled squares), incubation with 11-cis-retinal produced a large change in sensitivity (filled triangles).

\section{Regeneration of G90D pigment in isolated ROS membranes}

The results in Figure $6 B$ suggest that application of 11-cis-retinal can produce nearly complete regeneration of the G90D pigment. Because our ability to regenerate G90D opsin is central to the interpretation of our experiments, we also investigated the effect of 11-cis-retinal application on G90D opsin in isolated ROS membranes. These experiments were done in the following way (see Materials and Methods). Isolated ROS membranes from either Rho+/+;Rpe65-/- or D+/-; Rpe65-/-; Rho-/- mice were regenerated in darkness with 11-cis-retinal. The absorbance of the regenerated pigment was determined at $500 \mathrm{~nm}$ before and after bleaching, and the concentration of WT or G90D rhodopsin was calculated from the difference absorbance and the molar extinction coefficient of 40,000 , assumed to be the same for both 


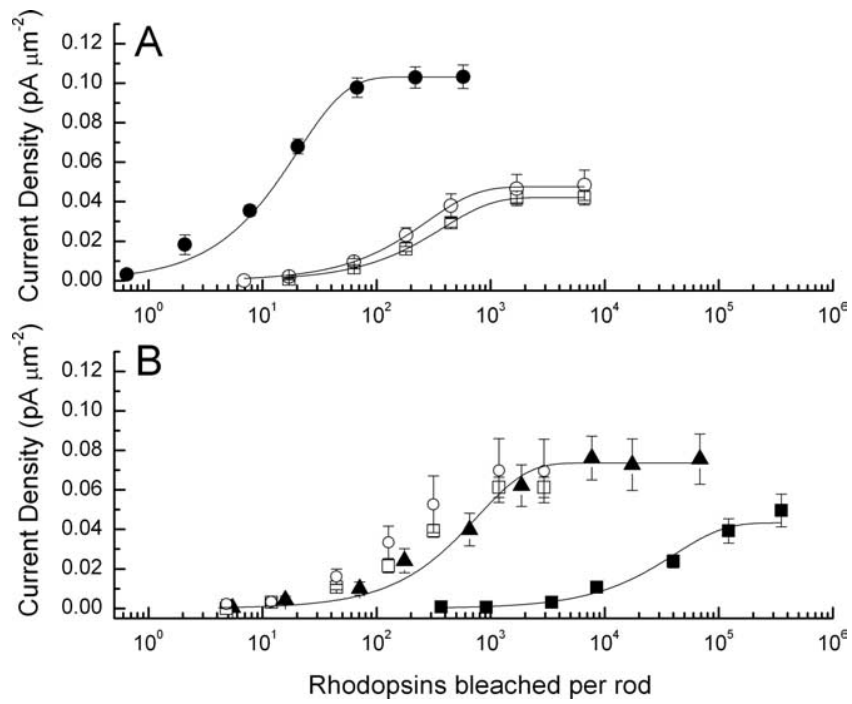

Figure 6. Addition of 11-cis-retinal to G90D rods. $\boldsymbol{A}$, Response-intensity curves for 30 $D+/+$ rods before treatment with retinal (open squares) and $15 \mathrm{D}+/+$ rods after $1-3 \mathrm{~h}$ of vesicle incubation (open circles). Measurements were made from rods from the same retinas and were independent from those shown in Figure $1 B$. Current densities were calculated by dividing by outer segment area of $99 \mu \mathrm{m}^{2}$; collecting area was 0.40 . Curves are fits to Equation 1 with values of $k$ of 0.00263 for open squares before vesicle incubation, and 0.0036 for open circles after vesicle incubation. Small shift in curves was not statistically significant (see Results). Filled circles and curve are for WT rods shown for comparison and were taken from Figure $1 B$. $\boldsymbol{B}$, Addition of vesicles to $D+/-; R h-/-$ rods with or without the RPE65 isomerase. Filled squares are mean responses from $24 D+/-; R h-/-; R p e 65-/-$ rods before addition of vesicles. Current density was calculated from outer segment area of $40.5 \mu \mathrm{m}^{2}$; collecting area was 0.06 (see Results). Filled triangles are mean responses from $24 D+/-; R h-/-$; Rpe65-/- rods after addition of vesicles containing 11-cis-retinal. Curves fitted to filled squares and triangles are Equation 1 with $k$ values of $2.4 \times 10^{-5}$ before and $1.3 \times 10^{-3}$ after. Open squares and circles give response-intensity data from $5 \mathrm{G}+/-; R \mathrm{~h}-/-; R p e 65+$ rods before addition of vesicles and $4 \mathrm{G}+/-; R h-/-; R p e 65+$ rods after vesicle addition. Outer segment area was $69 \mu \mathrm{m}^{2}$ and collecting area 0.28 (see Results). Error bars indicate $S E$.

pigments. The concentration of G90D pigment was corrected for the 0.91 absorbance efficiency at 500 relative to WT rhodopsin. After performing these calculations, we loaded three different amounts of WT and G90D pigment (17.6, 35.3 and $53 \mathrm{ng}$ ) onto an SDS gel (Fig. 7, inset) for immunoblot with an antirhodopsin polyclonal antibody. In Figure 7 , we plot on the ordinate the mean immunoblot intensities from four experiments, measured with chemilumiscence and quantified by densitometry as described in the Materials and Methods section; and on the abscissa, we give the calculated amount of pigment loaded onto the gel as determined from the absorbance after regeneration with 11-cisretinal. The results for WT and G90D pigment are nearly identical: the mean calculated ratio of the intensity of the immunoblot signal for G90D and WT pigment at the three concentrations of pigment loaded onto the gel was $1.02 \pm 0.04$ (mean $\pm \mathrm{SE}$ ). We also compared prebleached samples of outer segment membranes from $\mathrm{D}+1+$ mice containing the normal complement of the RPE65 isomerase. These results (data not shown) again demonstrate that the G90D pigment in mouse rods was regenerated to the same extent as the WT pigment: the mean calculated ratio of the intensity of the immunoblot signal for G90D and WT pigment at the three concentrations of pigment loaded onto the gel from four experiments was $1.08 \pm 0.06$.

\section{Desensitization in G90D rods is not produced by transitions from $R h$ to $R h^{*}$}

The experiments of Figures 5-7 indicate that the desensitization of G90D rods is unlikely to be produced by unregenerated opsin

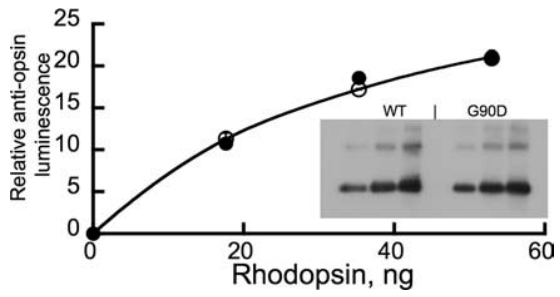

Figure 7. Regeneration of WT and G90D opsin in rod outer segment membranes. ROS membranes completely lacking regenerated pigment were isolated from $R h O+/+; R p e 65-1-$ and $D+/-; R$ Re65 - / - ; Rho-/- mice and regenerated with 11-cis-retinal as described in Materials and Methods. Pigment from rods of wild-type mice (open circles) and G90D mice (filled circles) was loaded onto an SDS gel at equal quantities of 17.6, 35.3, and $53 \mathrm{ng}$, as calculated from the absorbance at $500 \mathrm{~nm}$, and the pigment was then subjected to immunoblotting with an antirhodopsin polyclonal antibody (0lshevskaya et al., 2004). The strength of the immunoblot signal was measured with chemilumiscence and quantified by densitometry as described previously (0lshevskaya et al., 2004). The ordinate gives the average optical density of each band multiplied by the area of each band and has been plotted in arbitrary units; the abscissa gives the amount of WT and G90D pigment loaded onto the gel. The equal amounts of signal for the two kinds of pigment shows that there is no difference in their extent of regeneration with 11-cis-retinal.

but is rather the result of activation of the visual cascade by some form of the mutant rhodopsin. One possibility is that G90D rhodopsin produces an abnormally high rate of thermal transitions in darkness to metarhodopsin II or Rh* (Sieving et al., 1995, 2001; Jin et al., 2003). WT rhodopsin has been shown to produce single-photon events in darkness which are identical in waveform to single-photon events produced by real light (Baylor et al., 1980). The thermal events produced by WT rhodopsin are rare, indicating an extraordinarily low rate of spontaneous transition of the pigment to its active form. If G90D rhodopsin were to produce similar events but much more frequently, the noise generated by the mutant pigment should be similar to that produced by real light.

We tested this possibility in the following way. We recorded current noise from $\mathrm{D}+$ rods in darkness in segments of $10 \mathrm{~s}$ duration; 30 such segments were recorded from each of 12 rods both in the dark and in the presence of saturating light. From these recordings, we calculated the power spectrum for each rod independently in light and dark (see Materials and Methods). On the assumption that the spectrum in saturating light (when the channels are closed) represents instrument noise, and that the noise spectra produced by the cell and by our apparatus are independent from one another, we subtracted the noise in saturating light from the noise in the dark (Rieke and Baylor, 1996; Burns et al., 2002). The differences were then averaged over the 12 rods and are given (with SE) as the open triangles in Figure 8. Similar measurements were then made from WT rods and are shown as the filled squares. If the G90D rhodopsin were to produce more frequent spontaneous thermal events than WT rods, this should be reflected in a difference in the noise spectra, and we would expect the open triangles to lie above the closed squares. This may occur in the region of the spectrum from $\sim 4-10 \mathrm{~Hz}$, but the difference is small.

We then measured current noise in the same $12 \mathrm{WT}$ rods exposed to steady background light of an intensity of 251 photons $\mu \mathrm{m}^{-2} \mathrm{~s}^{-1}$ or $\sim 125 \mathrm{Rh}^{\star}$ per rod, nearly the same as our estimate of $130 \mathrm{Rh}^{\star}$ for the equivalent background light of $\mathrm{D}+$ rods. The noise in saturating light was again subtracted from the noise in the presence of the background light, and the averaged spectrum was plotted as the filled circles in Figure 8. There is now a large increase in the noise particularly in the region between $\sim 0.2$ and 


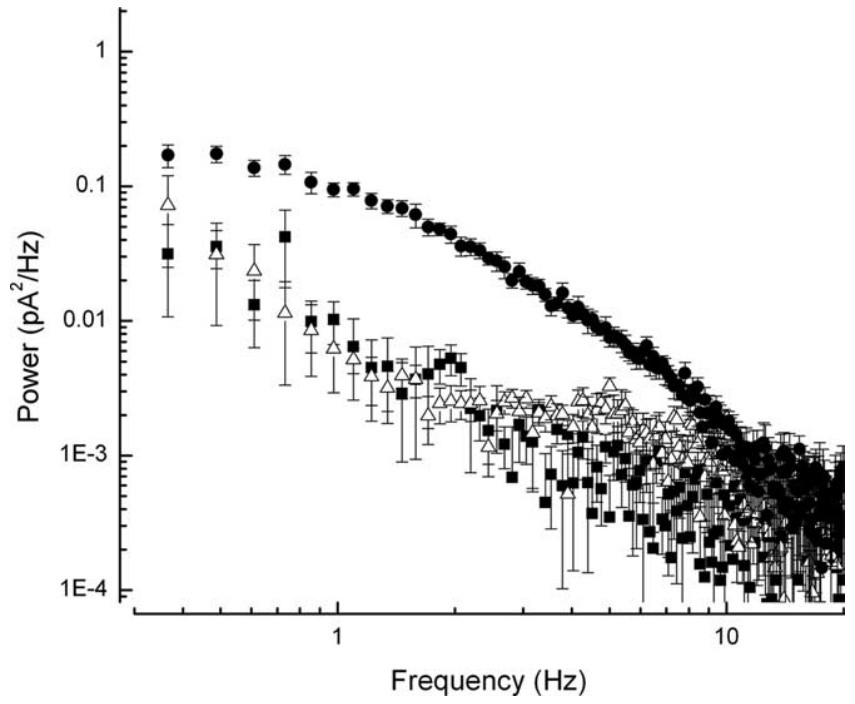

Figure 8. Noise measurements from D+ and WT rods. Spectra are means from 25 to 30 segments of circulating current each 9 s long for each rod in each condition (see Materials and Methods). Spectra were recorded from $12 \mathrm{D}+$ rods in darkness and in the presence of a saturating light of $7.9 \times 10^{3}$ photons $\mu \mathrm{m}^{-2} \mathrm{~s}^{-1}$. We assumed that the spectrum in saturating light (when outer segment channels were closed) represents instrumentation noise independent of cellular noise, and we subtracted the mean spectrum in saturating light from the spectrum in darkness. This difference spectrum is shown for the $12 \mathrm{D}+$ rods as the open triangles. A similar procedure for 12 WT rods gave the difference spectrum plotted as the closed squares. We then measured the noise spectrum from these same 12 WT rods in the presence of a background light of 251 photons $\mu \mathrm{m}^{-2} \mathrm{~s}^{-1}$, nearly equal to the equivalent light of $D+$ rods of 264 photons $\mu \mathrm{m}^{-2} \mathrm{~s}^{-1}$. The WT spectrum in saturating light was again subtracted from the spectrum in the background, and this mean difference spectrum is shown as the closed circles. Error bars indicate SEs.

$10 \mathrm{~Hz}$. Because this background light produces a decrease in sensitivity similar to that produced by the equivalent background in $\mathrm{a} \mathrm{D}+$ rod, the much larger noise in the WT rod shows that $\mathrm{D}+$ is unlikely to be producing thermal isomerizations of $\mathrm{Rh}^{\star}$ at a rate sufficient to account for the equivalent background.

\section{Discussion}

Our results show that mouse rods with the G90D mutation act as if in the presence of continuous background light (Sieving et al., 1995, 2001; Jin et al., 2003). The photoreceptors have a diminished dark current and sensitivity (Fig. 1), decreased outer segment free $\mathrm{Ca}^{2+}$ (Fig. 2), and acceleration of both $\tau_{\text {REC }}$ (Fig. 3) and $\tau_{\mathrm{D}}$ (Fig. 4), much like WT mouse rods illuminated with steady light (Mendez et al., 2001; Burns et al., 2002; Makino et al., 2004; Fan et al., 2005; Woodruff et al., 2008). These effects are consistently greater for homozygous G90D mice $(\mathrm{D}+/+)$ than for heterozygous $(\mathrm{D}+)$.

The species of G90D pigment responsible for activating the cascade and producing the equivalent background is unlikely to be unregenerated G90D opsin, as has been previously supposed (Rao et al., 1994; Rao and Oprian, 1996; Jin et al., 2003). In 15 experiments with $\mathrm{D}+/+$ rods (Fig. $6 \mathrm{~A}$ ) and seven with $\mathrm{D}+$ rods (data not shown), we were unable to detect any significant effect of application of exogenous chromophore on sensitivity or response waveform. The absence of an effect cannot be attributed to our failure to regenerate opsin with lipid vesicles containing chromophore, because when vesicles were added to WT opsin in Rpe65-1- rods, the photoreceptor sensitivity and response waveform recover essentially to those of a dark-adapted WT rod (Fig. 5). Furthermore, when 11-cis-retinal was added to $D+/-$; Rho-/-;Rpe65-/- rods, which also contained a substantial amount of opsin as G90D opsin, there was again a large recovery of sensitivity (Fig. $6 \mathrm{~B}$ ), not to the level of a dark-adapted WT rod but rather to that of a $D+/-; R h o-/-; R p e 65+/-$ rod having a functional gene for the RPE65 isomerase. Finally, the addition of 11-cis-retinal to isolated ROS membranes showed no significant difference in the efficiency of regeneration of G90D and WT opsin in vitro. These experiments make it highly unlikely that unregenerated opsin plays a significant role in producing the desensitization in a mammalian rod.

Our results appear to disagree with those of Jin et al. (2003). They showed that when mammalian G90D rhodopsin is expressed in Xenopus rods, the Xenopus rods are desensitized and response decay is accelerated, and that both of these effects can be reversed by treating the rods with exogenous 11-cis-retinal. Because the methods we have used on mammalian rods are nearly identical to those used by Jin et al. (2003), it is difficult to understand why exogenous 11-cis-retinal should have produced a large increase in sensitivity and $\tau_{\text {REC }}$ in their experiments but no significant effect in ours. One possibility is that mammalian G90D pigment behaves differently when expressed in Xenopus and in mouse. Jin et al. (2003) report that expression of G90D rhodopsin amounting to only $0.01-0.3 \%$ of the endogenous pigment in Xenopus is enough to produce a nearly 10 -fold decrease in rod sensitivity. This sensitivity decrease is similar to the one we see in mice in a G90D heterozygote, when $50 \%$ of the pigment is present in the mutant form (Sieving et al., 2001). Mammalian G90D pigment is therefore of the order of $200-5000 \times$ more active in stimulating the transduction cascade when expressed in Xenopus than when expressed in mouse. The reason for this difference is unknown, but it suggests that mammalian pigments do not behave in the same manner when expressed in amphibians and mammals.

Our results appear also to be at variance with those of Rao et al. (1994), who showed that mammalian G90D opsin in vitro has of the order of $10-20 \%$ of the activity of $\mathrm{Rh}^{\star}$. We show in contrast that the G90D opsin expressed in mouse rods in vivo cannot be much more active than WT opsin in vivo, which is only of the order of $10^{-5}-10^{-4}$ as active as $\mathrm{Rh}^{\star}$ in mouse (Fan et al., 2005). This can be seen from the comparison of the response-intensity curve of Rpe65-/- rods in the absence of 11-cis-retinal (Fig. 5C, blue squares), which contain close to $100 \%$ WT opsin, with the curve for $D+/-; R h o-/-; R$ pe65-/- rods in the absence of 11cis-retinal (Fig. $6 B$, filled squares), which contain only about half as much total photopigment as Rpe65-/- rods but nearly all in the form of G90D opsin. The positions of these curve along the intensity axis are not markedly different (values of $k$ for fits to Eq. 1 differ by only a factor of 4). Any correction for the smaller outer segment diameter of $D+/-; R h o-/-; R$ pe65-/ - rods would move the filled squares in Figure $6 B$ farther to the left and make the difference even smaller.

If the G90D opsin were as active in vivo as Rao et al. (1994) claim it to be in vitro, the $D+/-; R h o-/-; R$ pe65-/- rods should be much more desensitized than Rpe65-/-, because the equivalent background produced by the G90D opsin should be as bright as a real light in a WT rod stimulating of the order of $5-10 \%$ of the total visual pigment per second. It is possible that G90D opsin in vivo is less active than in vitro because arrestin binds to photoactivated G90D pigment just as it does to WT rhodopsin (Burns et al., 2006; Vishnivetskiy et al., 2007). We were unable to assess the relative efficiency of arrestin binding to G90D and WT pigment, but we nevertheless have confirmed that photoactivated G90D in the presence of ATP does bind arrestin (supplemental Fig. 2, available at www.jneurosci.org as supplemental 
material). The quenching of photoactivated G90D by arrestin seems therefore a likely explanation for the difference between our measurements and those of Rao et al. (1994). Opsin in a G90D patient should also be bound to arrestin, and this would be a further argument that unregenerated G90D opsin is unlikely to be responsible for the desensitization of a dark-adapted G90D rod in vivo.

If the equivalent background is not produced by unregenerated G90D opsin, then it must be caused by some form of G90D rhodopsin, i.e., G90D opsin conjugated to 11-cis-retinal. It is unlikely to be produced by frequent, spontaneous transitions of G90D rhodopsin to metaII (or $\mathrm{Rh}^{\star}$ ), because these events would be expected to produce noise equivalent to that generated by real light. The results of Figure 8 show, however, that this is not the case. The behavior of a G90D rod resembles that of a bleached WT rod, in which WT opsin activates the visual cascade and desensitizes the photoreceptor (Cornwall and Fain, 1994; Melia et al., 1997; Fan et al., 2005), but does not produce an increase in the noise at a rate similar to that produced by background illumination (Jones, 1998).

We propose that G90D rhodopsin stimulates the cascade but with much lower gain than $\mathrm{Rh}^{\star}$, perhaps as the result of transient thermal changes in conformation of the G90D rhodopsin molecule to an active state capable of stimulating only one or a few transducin molecules before returning back to the inactive state. The low gain of the noise would reduce its amplitude compared with the noise produced by real light (Jones, 1998), and this would explain our failure to see an increase in the current noise of dark-adapted G90D rods similar to that of a WT rod stimulated with actual light. It is possible that the small increase in dark noise in a G90D rod between $\sim 4$ and $10 \mathrm{~Hz}$ in Figure 8 represents low-noise events produced by G90D cascade activation. The Fourier-transform infrared spectroscopic measurements of Zvyaga et al. (1996) suggest that G90D rhodopsin may have some of the structural features of $\mathrm{Rh}^{*}$, including a protonated carboxylic group at position $\mathrm{Glu}^{113}$ and an increased strength of hydrogen bonding of $\mathrm{Asp}^{83}$. These and/or other properties of the G90D rhodopsin may make it more likely to assume an active configuration. Our experiments may stimulate a renewed effort with structural techniques including modeling, spin label probes, NMR, and x-ray crystallography to understand how the G90D mutation alters the activity of rhodopsin.

Our experiments may also explain why patients with the G90D mutation do not recover sensitivity even after long periods of dark adaptation and provide the first evidence that a single amino-acid mutation in the rhodopsin sequence is sufficient to produce spontaneous activation of the transduction cascade by rhodopsin itself, leading to congenital night-blindness. Most patients with the G90D mutation have a normal amount of rhodop$\sin$ in the retina and structural preservation of rods, despite massive loss of rod function and impaired dim light vision on standard clinical tests, including electroretinography and darkadaptation (Sieving et al., 1995). Other patients, however, show the typical degenerative pattern of retinitis pigmentosa, in which rod cell loss leads subsequently to cone demise and profound blindness (Berson, 1993). The human G90D rhodopsin trait appears therefore to lie just at the clinical border between dysfunction and degenerative disease, and it offers an opportunity to probe further the mechanisms by which spontaneous activation of the visual transduction cascade leads to rod structural impairment and cell death (Fain, 2006).

\section{References}

Baylor DA, Matthews G, Yau KW (1980) Two components of electrical dark noise in toad retinal rod outer segments. J Physiol 309:591-621.

Berson EL (1993) Retinitis pigmentosa. The Friedenwald Lecture. Invest Ophthalmol Vis Sci 34:1659-1676.

Burns ME, Mendez A, Chen J, Baylor DA (2002) Dynamics of cyclic GMP synthesis in retinal rods. Neuron 36:81-91.

Burns ME, Mendez A, Chen CK, Almuete A, Quillinan N, Simon MI, Baylor DA, Chen J (2006) Deactivation of phosphorylated and nonphosphorylated rhodopsin by arrestin splice variants. J Neurosci 26:1036-1044.

Cornwall MC, Fain GL (1994) Bleached pigment activates transduction in isolated rods of the salamander retina. J Physiol 480:261-279.

Cornwall MC, Jones GJ, Kefalov VJ, Fain GL, Matthews HR (2000) Electrophysiological methods for measurement of activation of phototransduction by bleached visual pigment in salamander photoreceptors. In: Vertebrate phototransduction and the visual cycle. Methods in Enzymology, Vol 316 (Palczewski K, ed), pp 224-252. San Diego: Academic.

Fain GL (2006) Why photoreceptors die (and why they don't). Bioessays 28:344-354.

Fan J, Rohrer B, Moiseyev G, Ma JX, Crouch RK (2003) Isorhodopsin rather than rhodopsin mediates rod function in RPE65 knock-out mice. Proc Natl Acad Sci U S A 100:13662-13667.

Fan J, Woodruff ML, Cilluffo MC, Crouch RK, Fain GL (2005) Opsin activation of transduction in the rods of dark-reared Rpe65 knockout mice. J Physiol 568:83-95.

Field GD, Rieke F (2002) Nonlinear signal transfer from mouse rods to bipolar cells and implications for visual sensitivity. Neuron 34:773-785.

Gross AK, Xie G, Oprian DD (2003) Slow binding of retinal to rhodopsin mutants G90D and T94D. Biochemistry 42:2002-2008.

Humphries MM, Rancourt D, Farrar GJ, Kenna P, Hazel M, Bush RA, Sieving PA, Sheils DM, McNally N, Creighton P, Erven A, Boros A, Gulya K, Capecchi MR, Humphries P (1997) Retinopathy induced in mice by targeted disruption of the rhodopsin gene. Nat Genet 15:216-219.

Hurley JB, Ebrey TG, Honig B, Ottolenghi M (1977) Temperature and wavelength effects on the photochemistry of rhodopsin, isorhodopsin, bacteriorhodopsin and their photoproducts. Nature 270:540-542.

Jin S, Cornwall MC, Oprian DD (2003) Opsin activation as a cause of congenital night blindness. Nat Neurosci 6:731-735.

Jones GJ (1998) Membrane current noise in dark-adapted and lightadapted isolated retinal rods of the larval tiger salamander. J Physiol 511:903-913.

Krispel CM, Chen D, Melling N, Chen YJ, Martemyanov KA, Quillinan N, Arshavsky VY, Wensel TG, Chen CK, Burns ME (2006) RGS Expression rate-limits recovery of rod photoresponses. Neuron 51:409-416.

Lamb TD, McNaughton PA, Yau KW (1981) Spatial spread of activation and background desensitization in toad rod outer segments. J Physiol 319:463-496.

Lem J, Fain GL (2004) Constitutive opsin signaling: night blindness or retinal degeneration? Trends Mol Med 10:150-157.

Makino CL, Dodd RL, Chen J, Burns ME, Roca A, Simon MI, Baylor DA (2004) Recoverin regulates light-dependent phosphodiesterase activity in retinal rods. J Gen Physiol 123:729-741.

Melia TJ Jr, Cowan CW, Angleson JK, Wensel TG (1997) A comparison of the efficiency of $\mathrm{G}$ protein activation by ligand-free and light-activated forms of rhodopsin. Biophys J 73:3182-3191.

Mendez A, Burns ME, Sokal I, Dizhoor AM, Baehr W, Palczewski K, Baylor DA, Chen J (2001) Role of guanylate cyclase-activating proteins (GCAPs) in setting the flash sensitivity of rod photoreceptors. Proc Natl Acad Sci U S A 98:9948-9953.

Naash MI, Wu TH, Chakraborty D, Fliesler SJ, Ding XQ, Nour M, Peachey NS, Lem J, Qtaishat N, Al-Ubaidi MR, Ripps H (2004) Retinal abnormalities associated with the G90D mutation in opsin. J Comp Neurol 478:149-163.

Olshevskaya EV, Calvert PD, Woodruff ML, Peshenko IV, Savchenko AB, Makino CL, Ho YS, Fain GL, Dizhoor AM (2004) The Y99C mutation in guanylyl cyclase-activating protein 1 increases intracellular $\mathrm{Ca}^{2+}$ and causes photoreceptor degeneration in transgenic mice. J Neurosci 24: 6078-6085.

Pepperberg DR, Cornwall MC, Kahlert M, Hofmann KP, Jin J, Jones GJ, Ripps H (1992) Light-dependent delay in the falling phase of the retinal rod photoresponse. Vis Neurosci 8:9-18. 
Rao VR, Oprian DD (1996) Activating mutations of rhodopsin and other G protein-coupled receptors. Annu Rev Biophys Biomol Struct 25:287-314.

Rao VR, Cohen GB, Oprian DD (1994) Rhodopsin mutation G90D and a molecular mechanism for congenital night blindness. Nature 367:639-642.

Redmond TM, Yu S, Lee E, Bok D, Hamasaki D, Chen N, Goletz P, Ma JX, Crouch RK, Pfeifer K (1998) Rpe65 is necessary for production of 11cis-vitamin A in the retinal visual cycle. Nat Genet 20:344-351.

Rieke F, Baylor DA (1996) Molecular origin of continuous dark noise in rod photoreceptors. Biophys J 71:2553-2572.

Robinson PR, Cohen GB, Zhukovsky EA, Oprian DD (1992) Constitutively active mutants of rhodopsin. Neuron 9:719-725.

Sieving PA, Richards JE, Naarendorp F, Bingham EL, Scott K, Alpern M (1995) Dark-light: model for nightblindness from the human rhodopsin Gly-90 - > Asp mutation. Proc Natl Acad Sci U S A 92:880-884.

Sieving PA, Fowler ML, Bush RA, Machida S, Calvert PD, Green DG, Makino CL, McHenry CL (2001) Constitutive "light" adaptation in rods from G90D rhodopsin: a mechanism for human congenital nightblindness without rod cell loss. J Neurosci 21:5449-5460.

Tsang SH, Burns ME, Calvert PD, Gouras P, Baylor DA, Goff SP, Arshavsky VY (1998) Role for the target enzyme in deactivation of photoreceptor G protein in vivo. Science 282:117-121.

Van Hooser JP, Aleman TS, He YG, Cideciyan AV, Kuksa V, Pittler SJ, Stone EM, Jacobson SG, Palczewski K (2000) Rapid restoration of visual pigment and function with oral retinoid in a mouse model of childhood blindness. Proc Natl Acad Sci U S A 97:8623-8628.
Van Hooser JP, Liang Y, Maeda T, Kuksa V, Jang GF, He YG, Rieke F, Fong HK, Detwiler PB, Palczewski K (2002) Recovery of visual functions in a mouse model of Leber congenital amaurosis. J Biol Chem 277:19173-19182.

Vishnivetskiy SA, Raman D, Wei J, Kennedy MJ, Hurley JB, Gurevich VV (2007) Regulation of arrestin binding by rhodopsin phosphorylation level. J Biol Chem 282:32075-32083.

Woodruff ML, Sampath AP, Matthews HR, Krasnoperova NV, Lem J, Fain GL (2002) Measurement of cytoplasmic calcium concentration in the rods of wild- type and transducin knock-out mice. J Physiol 542:843-854.

Woodruff ML, Wang Z, Chung HY, Redmond TM, Fain GL, Lem J (2003) Spontaneous activity of opsin apoprotein is a cause of Leber congenital amaurosis. Nat Genet 35:158-164.

Woodruff ML, Olshevskaya EV, Savchenko AB, Peshenko IV, Barrett R, Bush RA, Sieving PA, Fain GL, Dizhoor AM (2007) Constitutive excitation by Gly90Asp rhodopsin rescues rods from degeneration caused by elevated production of cGMP in the dark. J Neurosci 27:8805-8815.

Woodruff ML, Janisch KM, Peshenko IV, Dizhoor AM, Tsang SH, Fain GL (2008) Modulation of PDE6 turnoff during background illumination in mouse rod photoreceptors. J Neurosci 28:2064-2074.

Zvyaga TA, Fahmy K, Siebert F, Sakmar TP (1996) Characterization of the mutant visual pigment responsible for congenital night blindness: a biochemical and Fourier-transform infrared spectroscopy study. Biochemistry 35:7536-7545. 